\title{
ENCONTRAR LO POÉTICO DONDE NO LO HAY: LITERATURA Y HORROR
}

\author{
ENCONTRAR O POÉTICO ONDE NÃO HÁ: LITERATURA E HORROR
}

\author{
Estefanía Luján Di Meglio ${ }^{1}$
}

RESUMEN: El presente trabajo analiza las formas en las que la memoria y el testimonio por la última dictadura en Argentina se relacionan con los textos literarios. Para ello, parte de algunas conceptualizaciones teóricas de Walter Benjamin sobre la literatura y la historia. En una segunda parte, recoge ciertas caracterizaciones del testimonio y la memoria histórica, individual y colectiva. La última parte analiza discursivamente paratextos de dos textos literarios de la serie literaria sobre la dictadura (Procedimiento. Memoria de La Perla y La Ribera de Susana Romano Sued y La venganza y otros relatos de Ulises Gorini) que plantean una deliberada opción por la forma literaria en tanto resulta idónea para la representación de lo traumático, precisamente por compartir rasgos con lo testimonial y la memoria. De esta manera, la literatura y su forma rescatan lo que queda fuera de otros discursos sociales.

Palabras clave: Walter Benjamin; dictadura argentina; testimonio; memoria; literatura.

RESUMO: $O$ trabalho analisa as formas em que a memoria e o testemunho se interligam com a literatura. A primeira parte introduze algumas conceituaçãoes de Walter Benjamin sobre a literatura e a história. Na segunda parte, recolhe caracterizaçãoes sobre o testemunho e memoria pessoal e coletiva. A última parte analisa os paratextos de dois textos literários da última ditadura argentina (Procedimiento. Memoria de La Perla y La Ribera de Susana Romano Sued y La venganza y otros relatos de Ulises Gorini). Estes paratextos apresentam a deliberada opção por a forma literaria. A literatura é pertinente para representar o traumático, exatamente porque compartilhe traços com o testemunhal e memorial. A literatura salva aquele que resta por fora de otros discursos.

Palavras-chave: Walter Benjamin; ditadura argentina; testemunho; memoria; literatura.

El poeta es un motor de alta frecuencia espiritual, es quien da vida a lo que no la tiene; cada palabra, cada frase adquiere en su garganta una vida propia y nueva, y va a anidarse palpitante de calor en el alma del lector.

Vicente Huidobro, "Manifiesto del creacionismo"

\footnotetext{
${ }^{1}$ Profesora y Licenciada en Letras por la Universidad Nacional de Mar del Plata-UNMDP, Argentina. Ce.Le.His. Universidad Nacional de Mar del Plata, Argentina. Becaria doctoral de CONICET.
} 


\section{Introducción}

En Argentina, la serie narrativa literaria sobre la última dictadura comienza desde el mismo momento del gobierno de facto. El presente trabajo tiene por objetivo estudiar ciertos rasgos de lo literario que lo convierten en terreno idóneo para elaborar algunas problemáticas vinculadas al campo de la memoria histórica. Entendemos que la literatura es fin en sí misma y a la vez medio que permite estudiar ciertas manifestaciones de lo social. La hipótesis consiste en concebir la escritura literaria como uno de los campos privilegiados para testimoniar el horror y contribuir a la memoria histórica, debido a que comparte con estos géneros discursivos (el de la memoria y el testimonio) muchas de sus características, no sistematizables mediante otros discursos. En otras palabras, la especificidad de lo literario permite, sin reducirla, dar cuenta de la lógica paradójica del horror.

El artículo se compone de tres partes, bien diferenciadas en su estructura, pero estrechamente relacionadas entre ellas. La primera estudia ciertas características del hecho literario y de la historia a partir de algunos postulados de Walter Benjamin. El segundo apartado es un breve resumen teórico de determinados rasgos específicos del testimonio sobre lo traumatizante, así como de los mecanismos y trabajos de la memoria. El objetivo último radica en sentar las bases para finalmente, en la última parte, establecer esta especie de homología entre el funcionamiento de la memoria y la escritura del testimonio y la simbolización literaria del horror. Así, la parte final del trabajo consiste en un comentario sobre dos textos a modo de ejemplo ilustrativo: a través de los paratextos de estos dos libros que tematizan y abordan el horror de la dictadura es posible observar los modos en los que los procedimientos y las especificidades literarias se vislumbran como vía privilegiada al momento de intentar poner el trauma en palabras.

\section{El todo por la parte. La escritura desde las ruinas}

Walter Benjamin, materialista histórico -aunque no tanto según su amigo Theodor Adorno y el resto de los frankfurtianos- presenta la imagen del escritor como la de un flâneur (2008, p. 173). Se trata de una figura equivalente a la del trapero, homóloga del escritor, que moldea precisamente los restos que la sociedad descarta porque no producen ganancia, puesto que son justamente eso: restos, ruina, pura negatividad que se halla al margen y que permanece en los bordes de lo útil, de lo que tiene una función, en última instancia, de lo productivo. El escritor trabaja, pues, con la ruina (elemento barroco tan del gusto de Benjamin), el fragmento, lo inorgánico. Moldea su escritura, como un artesano de la palabra y del decir, con aquello que otros ámbitos de lo social -y otras discursividades- desechan por marginal, accesorio o irrelevante. Ante tal estado de cosas, el lugar que le cabe a la literatura no es de la norma sino el de la anomia, las discontinuidades, lo alternativo y lo singular. En Argentina, la ficción literaria sobre la última dictadura se funda en este espacio en el que se habla de un todo a partir de los restos, pero también de un resto sin todo, de una realidad, partiendo de sus bordes y no de su centro, pues se trata de un centro (el núcleo de lo traumático) al que, por lo inefable del horror, no puede accederse. Esta literatura habla de lo que otros discursos, deliberadamente o no, callan. $\mathrm{O}$, también, tematiza lo que sí ponen en escena otros discursos, pero con mecanismos singulares a su quehacer artístico, tanto que termina por construir nuevas perspectivas y nuevas formas de percibir el mismo objeto. La serie narrativa acerca de la dictadura potencia estos 
modos del decir particulares de la ficción literaria en general, trabajando con la polisemia, la contradicción, las situaciones paradojales y no resueltas, la torsión de temas y motivos, la hipérbole, la metáfora que dice lo mismo que el lenguaje pero de una forma diferente y, por ello, termina por producir un plus significante. Por sus mismas características, la representación del horror que supuso la experiencia dictatorial encuentra en el estatuto de lo literario un dispositivo de escritura apropiado, que le provee de estrategias enunciativas homólogas a la naturaleza contradictoria, polisémica, fragmentaria e hiperbólica de su enunciado, del testimonio y de la memoria, a los que se asocia. La literatura se concentra en el detalle aparentemente superfluo pero el cual hace a una totalidad descoyuntada que no puede prescindir de él. Benjamin ha dejado al descubierto su gusto por el detalle, aquel que Arendt destacara en Hombres en tiempos de oscuridad (1990, pp. 149-150) y que se convirtiera casi en fruición: con su afán de coleccionista desplazaba el centro de la acción a la descripción de los detalles. Frecuentemente, al hablar de otros escritores los críticos no hacen más que aludir a sí mismos, como en una mirada especular efectuada a través de la literatura. Así lo hizo Benjamin al referirse a autores como Kafka, de quien señaló que, en la mayor parte de sus textos, describía un mundo complementario pero sin hacer explícito el todo del que se desprendía tal complemento. Y así lo creía de la narración histórica. En "Sobre el concepto de historia", declara: "El cronista que narra los acontecimientos sin distinguir los grandes de los pequeños da cuenta de la siguiente verdad: la historia no pierde nada de lo que alguna vez aconteció" (Tesis III) (2009, p. 133). A menudo es el literato quien actúa como cronista y orfebre de los pormenores en los que nada se pierde. Éste es el lugar que le cabe a la literatura, empeñada en construir ciertos textos desde el hueco entre las ruinas, en hacer palabra de los silencios de la historia -de una historia que se deshace en la maraña de su mismo horror-, en fundar un lenguaje en el cual, paradójicamente, no hay más que ausencia de signos por acción de lo inhumano. Sin buscarlo y sin estar obligada a hacerlo, la literatura muestra, por medio de estrategias ajenas a otros discursos, instantes de verdad (el contenido de verdad de la obra de arte según Adorno y Benjamin), al decir de Arendt, quien estaba convencida de que se precisa de aquellos que piensan poéticamente -de allí que en una de las partes de su libro llame a Benjamin "el pescador de perlas"- que modulan un pensamiento en clave artística, a los fines de poder poner nombre a las cosas que no lo tienen. De allí también que el pensamiento de Benjamin estuviera articulado en clave poética. Arendt predica de él: ${ }^{2}$

Las metáforas son los medios por los cuales se logra en forma poética el carácter único del mundo. Lo que resulta tan difícil de comprender sobre Benjamin es que sin ser poeta pensaba poéticamente y por lo tanto consideraba la metáfora como el don más importante del lenguaje. La

\footnotetext{
${ }^{2}$ Beatriz Sarlo, en sus Siete ensayos sobre Walter Benjamin (2011), se refiere a este pensar poéticamente que repara en lo extraño, lo individual, lo particular, lo fragmentario, el detalle, la excepción: "El método poético en acción: Benjamin es sensible a lo más extraño, a lo excepcional, a lo fuertemente individual de la experiencia; descubre en lo raro el significado general, en lugar de buscar lo general en lo habitual y en la acumulación de lo mismo. Su mirada es fragmentaria, no porque renuncie a la totalidad, sino porque la busca en los detalles casi invisibles. Construye un conocimiento a partir de citas excepcionales y no sólo de series de acontecimientos parecidos" (p. 33). Por ello, su mirada es la de Medusa: "La originalidad de Benjamin se manifiesta en el trabajo de atrapar lo verdaderamente significativo en lo pequeño y lo trivial. Como Baudelaire, descubrió en la moda, en las colecciones, en los panoramas, el espíritu de una época en la que no puede captarse en sus grandes movimientos sino en la insignificancia aparente del detalle, abstraído, recortado y fijado por la mirada de Medusa, como Benjamin llama a la mirada de los surrealistas. El ojo ilumina lo inusual y lo particular con la certeza de que allí hay una clave. La mirada de la Medusa captura lo fugitivo, lo fija como un alfiler fija la mariposa a la colección” (p. 42).
} 
"transferencia" lingüística nos permite dar forma material a lo invisible (1990, p. 152).

En su artículo "El surrealismo. La última instancia de la inteligencia europea" (2009) Benjamin formula la categoría de iluminaciones profanas. Ellas se producen por la coexistencia de imágenes ${ }^{3}$ o elementos aparentemente sin relación entre sí pero que, al estar juntos y por ese vínculo sin relación, producen una iluminación, algo así como una epifanía, una revelación. El procedimiento tiene alcances y consecuencias similares a las del concepto de ostranenie de los primeros teóricos de la literatura, los formalistas rusos. La distancia operada por extrañamiento permite ver el objeto con una percepción desautomatizada a través de la singularización, como si se lo observara por primera vez, así como lo querían también los vanguardistas. La noción de iluminaciones profanas se relaciona además con los procedimientos propios del alegorista -y del coleccionista, tal como lo era Benjamin-, en tanto que construyen sentido al reunir fragmentos aislados de la realidad, modificando el contexto original de cada uno de ellos. No es otro el mecanismo de funcionamiento del lenguaje poético, que con sus artificios deja al descubierto lo no visto a causa de costumbre de la mirada. La literatura, por medio de sus estrategias y operatorias del discurso, y a partir de sus propios procedimientos de ficcionalización, desautomatiza la mirada anquilosada y presenta a menudo los objetos y acontecimientos a su arbitrio, sin relaciones lógicas que la hagan equivalente a otros discursos. ${ }^{4}$

En la conocida Tesis VII sobre filosofía de la historia, Benjamin sentencia que "no hay nunca un documento de la cultura que no sea, a la vez, uno de la barbarie" (2009, p. 138). Por esta razón, el autor emplea la metáfora impura de "cepillar a contrapelo la historia" (2009, p. 138). Su propia historia de persecución y exilio ${ }^{5}$ lo llevará a reafirmar estas tesis y a ponerlas en práctica en una tarea de "redención" de los tesoros culturales y de la historia misma, una historia que es escrita y monopolizada por los "vencedores", por las versiones oficiales y funcionales al poder. Tal afirmación es operativa para concebir cierta literatura que, como la que escribe la última dictadura en Argentina, se ha dedicado a releer esa historia. A contrapelo de la historia oficial, elaborada por los vencedores, pero también de otras historias marginales, lo literario crea nuevas historias que ponen en jaque los derroteros de las páginas oficiales de la historiografía; que incluso cuestiona las posibilidades reales de asertividad y de narrar los hechos de manera acabada y total, comenzando por plantear que no existe una historia única y dejando al descubierto los mecanismos constructivos del relato historiográfico que dan cuenta de que él mismo es un constructo, una mímesis de lo sucedido que no presenta los hechos en sí, sino que los (re)construye y los (re)presenta. Tal como sostiene Jacques Rancière en Política de la literatura (2011), enmarcado en el paradigma de la deconstrucción de los saberes establecidos y aceptados, "el escritor es el arqueólogo que hace hablar a los testigos mudos de la historia común", es quien con su tarea "exhuma los testimonios que la sociedad descarta" (p. 32 y 39 ). Como la mirada del arqueólogo, atenta a los restos sepultados, la del escritor es una observación de etnógrafo que se posa, paciente, en los testimonios mudos y relegados por el resto de las disciplinas.

\footnotetext{
${ }^{3}$ La imagen cobra suma relevancia en el pensamiento de Benjamin. La idea de la figura del pasado como imagen se corresponde con ese instante de relampagueo en el que el pasado se actualiza (2009).

${ }^{4}$ Así como en otros textos, en los párrafos iniciales de "Las Afinidades electivas, de Goethe” (2006) Benjamin define lo que entiende por crítica literaria, destacando la noción de contenido de verdad como objetivo de aquella: "La crítica se ocupa del contenido de verdad de una obra de arte, el comentario de su tema” (p. 125).

${ }^{5}$ En sus ensayos sobre Benjamin (2011), Sarlo reescribe, por inversión, la tesis VII y la aplica a la propia vida del alemán, estableciendo a propósito de su suicidio -visto en clave de redención- que no hay documento de barbarie que no sea, a su vez, uno de civilización.
} 
El arte en general y la literatura en particular se definen por lo paradójico, lo contradictorio, por la naturaleza del oxímoron. De allí que se convierta en terreno propicio para representar, cuestionar y dialogar con las complejidades de lo social y aquellos aspectos confinados al lugar de lo ignoto. En este sentido, la literatura acerca de los traumas históricos se construye sobre un saber ignorado en dos niveles: porque trabaja con lo desconocido, por un lado y, por otro, porque incluso cuando exhibe cierto saber sobre determinada realidad, hay zonas de ese real inaprehensible que permanecen solapadas.

\section{De la problemática de la representación. Testimonio y memoria}

Carlos Gamerro explica, en una conferencia, cómo la problemática representación teatral del horror y del funcionamiento de la memoria encontró su solución casi en el mismo punto donde se originaba el problema. Cuenta que en la trasposición al teatro de su novela Las islas, cuando uno de los personajes recuerda el estaqueo de un soldado combatiente en Malvinas, se le planteó el problema de cómo mostrar que, mientras la acción transcurría normalmente, esa escena ocurría en la mente del personaje. Termina por resolver que al fin y al cabo es más "realista" que el recuerdo de esa acción se haga en simultáneo con lo que se está representando en escena en ese momento. En ese sentido, cree que es la representación es "más realista" puesto que exhibe los modos de funcionamiento de la memoria: el recuerdo que viene por asalto, irrumpiendo en el presente tal como el estaqueo irrumpía en el proscenio.

Los ejemplos podrían multiplicarse exponencialmente, pero sin ir más lejos, entendemos que el horror, junto con el sistema de vida que genera es, como dice uno de los personajes en la autoficción La resistencia (2018) de Julián Fuks, inverosímil. Este rasgo se debe, en parte, a la calidad de para-experiencia (el término es de Nancy) que exhibe lo inhumano, una realidad difícil de expresar por medio del lenguaje y los marcos interpretativos con los que cuentan los seres humanos (JELIN, 2012, p. 113). De allí que muchas veces sean la invención y la imaginación literarias las que mejor elaboren las paradojas propias de lo traumatizante, puesto que la literatura, en su misma esencia, trabaja con lo difícil, con lo paradójico, en la torsión de lo real inaprehensible, en las ruinas de la vivencia pero también de la palabra y el discurso (KOHAN, 2014, p. 169).

La representación por medio del lenguaje, el relato y el discurso instala la problemática relación entre las palabras y las cosas. Tal dificultad representacional se ve profundizada en el caso de las historias atravesadas por lo traumático. Cuenta Tzvetan Todorov (1970) que ya en el siglo $\mathrm{V}$ a.C. se genera la conciencia de que el relato y las cosas en sí mismas (los hechos, las historias, los objetos, las emociones) van por caminos diferentes. Es que los sofistas, preocupados por las estrategias retóricas que tienen como efecto el convencimiento de quien escucha, advierten esta realidad. Miles de años más tarde, los simbolistas, obnubilados por los misterios órficos del lenguaje, dudarán de la correspondencia entre el lenguaje y los objetos, entre las palabras y la realidad inaprehensible, con lo que notarán que no hay una relación de equivalencia entre ambos: la lengua es mediación, tanto que intentar mencionar el mundo significaría aprisionarlo. Por su parte, las vanguardias históricas -que abrevan de las fuentes de la poesía moderna- reconocen la no linealidad entre las palabras y las cosas que ellas designan: descubren la opacidad propia de lo lingüístico. De allí sus intentos de experimentación con todo lenguaje (pictórico, literario, escultórico, cinematográfico) y el convencimiento de que los mecanismos experimentales pueden redimir a las palabras de sus ataduras mediadoras. Precisamente por estas épocas, a comienzos del siglo pasado, emerge una figura central en la 
filosofía del lenguaje, que retoma la opacidad de lo lingüístico y su condición limitada al momento de la representación. Para el primer Ludwig Wittgenstein, el del Tractatus, el lenguaje no es más que un nombre de las realidades que componen el mundo, el que, por su parte, sólo puede captarse de manera fragmentaria y nunca acabada: "No hay ningún medio, según el autor, para describir la totalidad de las cosas que pueden ser nombradas; en otras palabras, la totalidad de todo cuanto hay en el mundo" (RUSSEL apud WITTGENSTEIN, 1973, p. 21). El lenguaje está imposibilitado de aprehender la realidad: "Sólo puedo nombrar los objetos. Los signos los representan. Yo solamente puedo hablar de ellos; no puedo expresarlos. Una proposición únicamente puede decir cómo es una cosa, no qué es una cosa" (WITTGENSTEIN, 1973, p. 55).

Los postulados de Michel Foucault, en la segunda mitad del siglo XX, adquieren fundamental importancia para entender el lenguaje como un medio de representación y no como la presentación misma de las cosas. En su ensayo Esto no es una pipa (2011), descubre los diferentes niveles en los que la representación a partir del lenguaje multiplica sus instancias mediadoras. Sin ir más lejos, apela al cuadro del surrealista belga René Magritte que da título a su texto, como punto de partida y de llegada en su estudio del lenguaje en tanto instrumento opaco de la expresión del mundo. No hay que olvidar que las formaciones teóricas francesas de los años sesenta abrevaron en las vanguardias artísticas de principios de siglo. El cuadro de la pipa que lleva como epígrafe "Esto no es una pipa" hace alusión, entre tantas otras sugerencias, a la no correspondencia directa entre las palabras y su referente; el lenguaje no presenta las cosas, sino que las (re)presenta. Como dirá Paul Ricoeur, finalmente, "toda la admirable fenomenología de la familia de las presentificaciones -ficción, 'pintura', recuerdo- demuestra un desdoblamiento fundamental entre representación y presentación” (2003, p. 153). Reflexiones análogas merece un procedimiento recurrente en el pintor belga, como lo es la figuración pictórica de un objeto que lleva como epígrafe el nombre de otro: el lenguaje no se corresponde con la realidad representada. Foucault retoma la idea vanguardista de que existe una escisión entre las palabras y lo que ellas designan. Como dijimos, esta problemática representacional se acentúa al momento del relato de lo traumatizante. De allí que el testimonio sobre el horror se presente como paradójico: vale por lo que falta en él.

\subsection{La paradoja del testimonio}

Una de las aristas de la paradoja del testimonio está dada por el hecho de la necesidad imperiosa de testimoniar sobre el horror como una forma de memoria individual y colectiva pero, al mismo tiempo, la dificultad de testimoniar a causa del carácter traumático y horroroso de los hechos. Giorgio Agamben, basándose en Primo Levi como "tipo de testigo perfecto" (2010, p. 14), y considerándolo así a partir del desplazamiento metonímico, delinea la "paradoja de Levi" (AGAMBEN, 2010, pp. 8-9). Como decíamos, la realidad sobre la cual hay que testimoniar escapa ella misma al lenguaje y a las palabras, al relato y al discurso, por ser una para-experiencia, una experiencia apartada de la lógica cotidiana, una realidad aporística por esencia. En efecto, uno de los aspectos paradójicos de los campos reside en que "Auschwitz es precisamente el lugar en que el estado de excepción coincide perfectamente con la regla y en que la situación extrema se convierte en el paradigma mismo de lo cotidiano" (AGAMBEN, 2010, p. 50). Será esta dinámica de regla y excepción la que lleve a Agamben a dimensionar los campos de concentración como paradigma biopolítico de lo moderno, uno en el que la biopolítica pasa a coincidir con la tanatopolítica. Reflexiones similares impone la potencial representación de la muerte en el universo concentracionario, donde según Agamben se da una 
imposibilidad para "identificar con certeza el crimen específico" (2010, p. 84): no hay parámetros para distinguir entre la entronización de la matanza administrada y la degradación de la muerte. Una de las variables redunda, pues, en esta dificultad de poner palabras a la experiencia vivida, lo que se ve ya en la dificultad de nominación del proceso histórico (Shoa, Holocausto, entre otros), como señala Anette Wieviorka (2017). Lo cierto es que en el sobreviviente se suscita esta necesidad imperiosa de testimoniar como pulsión verbalizadora, conjuntamente con la dificultad de hacerlo.

El aporte simbólico del testimonio, lo que él puede tributar en su dificultad semiótica de carencia de signo que compatibilice significado y significante, reside precisamente en lo que falta en él: en los restos, las fisuras, los espacios intersticiales entre unas ruinas que ni por separado ni juntas alcanzan a componer el horror pasado que persiste en el presente: "la riqueza de los testimonios no está constituida sólo por lo que 'dicen' y la forma en que lo hacen, sino también por lo que callan y omiten, por aquellos sentidos que están ocultos y presentes a la vez en los recuerdos, más allá de la narración puntual” (CARNOVALE, 2007, p. 174).

Daniel Link, escritor y crítico argentino, es uno de los autores que rastrea las formas propias del testimonio en relación con otros relatos y registros de los hechos. En efecto, el autor toma como bases de su concepción del testimonio las teorizaciones de Agamben:

Editor de la obra de Benjamin y uno de sus más agudos intérpretes, no es casual que tampoco para Agamben lo decisivo del testimonio se juegue no en el plano epistemológico (quanta de verdad) sino en el plano ético: la subjetividad se constituye (se hace y se deshace) en la experiencia radical de escritura que es el testimonio y no en la adecuación entre una vivencia y un texto que sería su mera transcripción (2008, p. 125).

Frente a esto, explica que las formas de valoración del testimonio no residen en los términos de lo verdadero o lo falso, puesto que él se constituye en lo experiencial:

El testimonio no está del lado de la verdad, sino del lado de la experiencia. Y la experiencia no es previa al acto de discurso en el que se constituye (la narración), como tampoco puede ser previo el sujeto al proceso mismo de subjetivación y de desubjetivación (ascesis) del que paradójicamente depende. Por eso mismo, la fuerza pedagógica del testimonio no se resuelve en sede judicial, epistemológica o estética, sino en sede ética (2008, p. 126).

El carácter eminentemente experiencial del testimonio viene dado por su condición de resultado de los trabajos de la memoria, que se define ella misma por ser subjetiva, emotiva, fragmentaria. Así lo entiende Paolo Montesperelli, quien caracteriza la memoria en su clásico enfrentamiento con la historia:

En esta continua modificación [de la memoria] existe una profunda diferencia con la historiografía; lo que constituye la memoria es la vivencia subjetiva, no el conocimiento "objetivo" de los hechos. Por eso, a menudo los protagonistas y los testigos de un acontecimiento o de una época no se reconocen en la reconstrucción de los historiadores. [...] La historia es más y menos que el pasado. Es interpretación, toma de distancia con el pasado. La memoria, en cambio, comporta la participación emotiva en él; se presenta como 
representación vaga, fragmentaria, incompleta, siempre tendenciosa; una reconfiguración del pasado sobre la base de las exigencias del presente (2004, p. 117).

Estas reflexiones acerca del carácter complejo, fragmentario y asistemático de la memoria (tanto individual como colectiva) nos conducen al segundo aspecto de este apartado.

\subsection{Del recuerdo a la memoria}

Sucede que la reconstrucción de los hechos que constituyen las vivencias está supeditada a los arbitrios de la memoria, siempre fragmentaria y selectiva (STEINER, 2009, p. 125; AUGÉ, 1998, p. 23). "La memoria no es un fiel reflejo del pasado sino una reconstrucción individual y social de ese pasado que incluye selección, interpretación y resignificación” (TEUBAL et al., 2010, p. 35), razón por la cual "en el tratamiento de la memoria hay que tener en cuenta también la contraparte no nombrada del recuerdo, o sea, el papel del olvido (CANCLINI, 2008, p. 28).

Si bien debemos diferenciar entre lo no dicho y lo indecible, la condición inefable de lo siniestro viene profundizada a priori por un conjunto de incertezas y de olvidos, en un relato en el que nada es plausible de contrastarse con una empiria absoluta, en cuanto que es el sujeto de la enunciación quien, con olvidos de por medio, reconstruye una historia. ${ }^{6}$ Todo esto no hace más que agudizar el carácter escurridizo de lo traumático. Así, toda historia de vida es, a fin de cuentas, una forma específicamente fragmentaria, parcial y subjetiva que conduce a una nueva percepción de la experiencia que permite la reconstrucción histórica (MEYER; SALGADO, 2002, p. 16).

El propio Benjamin reflexiona, En Infancia en Berlin hacia 1900 (1987), sobre el recuerdo y el olvido, presentándolos en su carácter recortado, involuntario y selectivo, a la vez que entiende ciertos olvidos como la activación de mecanismos de defensa en el individuo: "Jamás podremos rescatar del todo lo que olvidamos. Quizá esté bien así. El choque que produciría recuperarlo sería tan destructor que al instante deberíamos dejar de comprender nuestra nostalgia" (p. 76). En su libro En mi nombre. Historias de identidades restituidas (2014), Ángela Pradelli explica, desde una hermenéutica de los casos concretos, las diversas acciones que se hallan asociadas a la construcción de la memoria:

La memoria conserva pero también investiga, analiza. Nuestra memoria no es el puro recuerdo congelado, ni la copia del suceso, ni la reproducción mecánica del hecho, ni una repetición calcada. La memoria relaciona, interpreta. Cuando la memoria narra, el pasado se descontractura, tiene continuidad, avanza y es presente al mismo tiempo. Al narrar el pasado, la memoria le da densidad. Cuando escuchamos, leemos o contamos una historia, los hechos nos atraviesan el cuerpo y algo de la viscosidad y concentración de los acontecimientos se expresa también hoy en cada uno de nosotros (p. 15 y 194).

\footnotetext{
${ }^{6}$ Pradelli observa que "la memoria es dinámica y en sus movimientos hay preservación y hay borramientos, hay recuerdos y omisiones. En su propia construcción, la memoria se amplía, puede ajustarse, tener cada vez más precisiones, corregirse [...] Es una construcción laboriosa que nunca termina” (2014, p. 17).
} 
El papel del olvido y del silencio (intencionado o no) es resaltado por Jelin al momento de hablar de memoria colectiva:

En todo esto, el olvido y el silencio ocupan un lugar central. Toda narrativa del pasado implica una selección. La memoria es selectiva; la memoria total es imposible. No hay un único tipo de olvido, sino una multiplicidad de situaciones en las cuales se manifiesta una multiplicidad de formas de expresión de olvidos y silencios, con diversos "usos" (2009, p. 121).

Régine Robin presenta su caso particular, su propia experiencia (que tomará sobre todo en la tercera parte de su libro La memoria saturada) para ejemplificar: "En efecto, yo soy de la generación que conoció la Segunda Guerra Mundial. Por cierto, esos recuerdos son discontinuos, fragmentados, vagos, y por lo que respecta a algunos de ellos es difícil saber si se trata de hechos vividos o narrados" (2012, p. 17). Como se deduce de la cita, el recuerdo se halla condicionado y resulta construido desde el mismo momento en el que se perciben, experimentan y viven los sucesos, en una concepción bergsoniana del tiempo y del recuerdo. Como explica Paolo Virno, discípulo intelectual de Bergson, "Un hecho acaecido muchos años atrás es 'pasado' en una doble acepción: algo que fue percibido y algo que fue recordado mientras sucedía, un 'entonces' real y un 'entonces' virtual, un pasado ubicado cronológicamente y un pasado-en-general” (2003, p. 30). Además, tanto la percepción de los hechos como su posterior construcción por medio de la memoria y el recuerdo están sujetos a potenciales distorsiones, pasibles de presentarse a causa de la concurrencia de lo traumático (ROBIN, 2012, p. 29).

Lejos de invalidar la vivencia, las deformaciones del recuerdo pueden significar productividades y forman parte de esa experiencia que precisamente por ser traumática altera los datos que el sujeto percibe y procesa: "también los límites de la memoria, los errores del recuerdo pueden representar potencialidades útiles para releer el pasado, para interpretarse a sí mismos y para construir la propia identidad" (MONTESPERELLI, 2004, p. 8). Asimismo, los silencios y huecos forman parte de la constitución de tal memoria, tanto individual como colectiva, personal o histórica: "La multiplicidad y complejidad de las prácticas del recuerdo hacen indispensable reconocer que los silencios, las fracturas del relato y los dispositivos estéticos forman parte inherente del hacer memoria” (PIPER, 2009, pp. 154-155).

De igual manera, la memoria no está fijada de una vez y para siempre. Éste es el motivo que conduce a Michael Pollak a observar cómo las memorias son no solamente construidas, sino también deconstruidas (por otros y por los mismos autores de esas memorias) y reconstruidas (2006, p. 29). Es operativa la explicación que Enzo Traverso expone sobre el carácter abierto de la memoria y el modo por el cual se construye en perspectiva, con una mirada hacia atrás que la moldea de acuerdo a múltiples factores, entre los que se halla la adquisición de nuevas experiencias: "Debido a su carácter subjetivo, la memoria jamás está fijada; se parece más bien a una obra abierta, en transformación permanente" (2011, p. 22). En efecto, la distinción entre historia y memoria, así como el genocidio nazi y los relatos que confluyen en su construcción, reconstrucción y usos en torno a él son temas recurrentes en las investigaciones del historiador italiano. En su libro La memoria, la historia, el olvido (2003), Ricoeur distingue dos estatutos de realidad en cuanto a los hechos: por un lado, se presenta el hecho en sí, como entidad autónoma de la percepción; por otro lado, se halla el acontecimiento rememorado, como construcción de la percepción y del recuerdo del sujeto (p. 235 y 216). "El recuerdo es representación, re-presentación” (RICOEUR, 2003, p. 250). El filósofo francés se 
pregunta, guiado por una idea semejante a la anterior, sobre los mecanismos de reconstrucción de la memoria, que hacen a su misma esencia: "¿no es el olvido una cosa distinta de aquello que recordamos haber olvidado, porque lo recordamos y lo reconocemos?” (2003, p. 133). Una distinción semejante a la de Ricoeur señala uno de los adalides del giro lingüístico y del paradigma de la deconstrucción, Hayden White, quien a propósito del discurso historiográfico diferencia los acontecimientos (facts) de su construcción por medio del lenguaje y la narración, que viene a convertirlos en hechos (events) (2010). En el texto más representativo de sus postulados, Metahistoria. La imaginación histórica en el siglo XX (1992), analiza los principales cauces que siguió el pensamiento histórico durante el siglo pasado. Para ello, emprende un análisis epistemológico de los modos de narrar, llegando a establecer una de sus principales tesis, a saber, que no existen diferencias de forma entre el relato histórico y el relato de ficción, desde el momento en el cual el discurso histórico está constituido de lenguaje y por tanto emplea los mismos tropos que la ficción, con lo que ese discurso es tan ficticio como un texto literario. El relato histórico implica creación, motivo que lo asemeja, al punto de la indistinción, al relato ficcional. La memoria, al igual que la historia, es construcción, en al menos dos planos: en un primer momento, en el plano mental; en una segunda instancia, cuando lo memorial se articula en y por el lenguaje, es constructo retórico: "La memoria o conciencia no existen como tales, sino que son el producto de una construcción permanente e ininterrumpida, resultado de la sorprendente plasticidad del funcionamiento cerebral" (FEIERSTEIN, 2012, p. 28). Memoria e imaginación se vinculan por el carácter creativo de aquella: "la memoria no sería, desde esta perspectiva, una actividad reproductora de la realidad sino, por el contrario, una actividad profundamente creativa. Cada acto de memoria constituye un acto de imaginación" (FEIERSTEIN, 2012, p. 53). (Énfasis en el original).

La memoria es constructo en sí misma, una forma de creación, como lo planteara Gastón Bachelard (2000). La puesta en relato, la praxis escrituraria sería, entonces, una construcción en segundo grado, pero lo cierto es que la creación y la invectiva así como su carácter fragmentario y selectivo son rasgos que comparten la memoria y la literatura. Se nos dirá que también son característicos del discurso historiográfico (de hecho lo hemos visto con Hayden White), pero en literatura son rasgos que no sólo hacen a sus especificidades en mayor medida en la que pueden aparecer en el discurso histórico, sino que, por otra parte y lejos de despreciarlos, la literatura los dimensiona no como rasgos negativos, sino como rasgos portadores de un valor, justo allí donde otros discursos, signados tradicionalmente por una huella positivista difícil de abandonar, los descartan por su negatividad. La literatura en cambio prolifera en esa misma negatividad y la hace productiva. Lo literario, pues, recoge esos restos que los otros discursos sociales desestiman. Al igual que el trapero que recorre la ciudad sin un destino fijo, como quien vagabundea por las calles, atento a aquello que la sociedad capitalista descarta, seleccionando el material, atesorándolo como un coleccionista, descontextualizándolo y proveyéndolo de un nuevo uso, el escritor selecciona el material de su escritura entre las ruinas del lenguaje y de lo que la sociedad deja a un lado. Como lo veíamos con Benjamin, la literatura trabaja sobre esas ruinas: de la sociedad, de la historia, de los discursos.

\section{En clave literaria}

La literatura parte, con frecuencia, de la imposibilidad -en este caso, la imposibilidad de poner en palabras el horror, o, al menos, su núcleo duro-. Si hay algo certero que la define es la conciencia de las propias incertezas sobre las que se afirma. De ahí su carácter discontinuo, su 
afán por situarse en los intersticios desde donde surge su creación y su mímesis siempre inacabada. Así como la problemática de la representación se ve acentuada en el caso la representación de lo traumático (lo que dicho así constituye una paradoja), el carácter discontinuo de lo literario se profundiza cuando de horror se trata. La discontinuidad del trauma respecto de la experiencia corriente, esa irrupción violenta que todo lo desarticula (identidad, experiencia, lenguaje), tiene su homología en la discontinuidad del terreno representacional literario, en la no observancia de la literatura -una acción deliberada e irreverente- de la lógica y de lo que se entiende por sentido común: lo literario tiene sus propias reglas que lo hacen propicio a acoger lo que la sociedad descarta. No por otros motivos Rancière efectúa una inversión directamente proporcional al dictum adorniano sobre Auschwitz:

Hay que invertir, entonces, la por demás célebre frase de Adorno que decretaba la imposibilidad del arte después de Auschwitz. Es lo contrario lo que es verdadero: después de Auschwitz, para mostrar Auschwitz, solo el arte es posible, porque siempre es lo presente de una ausencia, porque su trabajo mismo es el de dar a ver algo invisible, a través de la potencia regulada de las palabras y de las imágenes, juntas o disjuntas, porque es, entonces, lo único capaz de volver sensible lo inhumano (2013, p. 46).

De allí que el horror de la dictadura encontrara la vía de manifestarse, desde los mismos tiempos en los que imperaba lo siniestro, mediante la praxis escrituraria de lo literario. Cuando no existían otras formas de hablar en medio del horror dictatorial, la literatura, en sordina, hizo oír su voz. Las novelas sobre la última dictadura argentina y el terrorismo de Estado emergen en medio de un discurso que, como los actores sociales que lo enuncian, se pretende monovalente. Al discurso autoritario y pretendidamente unívoco de los dictadores vienen a oponérsele discursividades literarias que surgen y se filtran por entre sus grietas (SARLO, 1987). La ficción literaria se articula como una práctica discursiva de resistencia, cuestionamiento y aún denuncia -en forma velada o explícita- del gobierno de facto. Una vez finalizado el régimen castrense, la literatura que escribe sobre él y aspectos que se le vinculan no se detiene. A medida que avanzan las décadas en democracia se producen novelas que tematizan el período, emprendiendo múltiples lecturas acerca de la experiencia dictatorial y añadiéndole, ahora, perspectivas sobre la postdictadura.

Los textos de esta serie narrativa en su conjunto, en una de las posibles lecturas, pueden considerarse como síntoma de un duelo no elaborado (a nivel individual y social) y, en esta dirección como índice de la necesidad de emergencia de memorias que han sido por largo tiempo "subterráneas" (retomando el concepto de Pollak): la proliferación de textos literarios sobre el período, que puede homologarse aproximadamente al procedimiento discursivo de la repetición (teniendo en claro que éste siempre implica diferencias), es pasible de ser leída como esa necesidad de duelo. En esta dirección, lo que dice de la historia Alessandro Portelli bien es funcional para entender la literatura: "La narración no es una mera representación de los eventos de la historia; es ella misma un evento de la historia, es algo que las personas hacen en el transcurso del tiempo y tiene efectos sobre los comportamientos colectivos e individuales" (2004, p. 35). El hecho de que se escriban textos sobre el pasado reciente se convierte en un fenómeno que no sólo permite reconstruir un contexto de producción donde se reescriben acontecimientos de la historia, sino que además puede dimensionarse como un hecho puntual y específico, el cual hace a esa misma historia que está reescribiendo y releyéndose. De la misma manera que la escritura del horror vivido en Argentina configura la cartografía de un duelo que 
ha quedado en un estado de limbo, la recurrencia a lo literario puede responder a la búsqueda de un terreno propicio que acoja lo excepcional e inasible de la vivencia traumática.

Lo literario está provisto de un rasgo homólogo al testimonio y a la memoria, donde lo no dicho, lo indecible, lo inenarrable, lo paradójico y lo fragmentario son el elemento que los convierte en equivalentes: se trata, incluso sin quererlo, de restituir un todo -siempre incompleto- a partir de fragmentos, de los silencios del discurso, de las ruinas sobre las que se construye ese discurso, por medio de huellas que aisladas y a la vez reunidas, puedan conducir a producir sentido. La memoria y el testimonio (y la memoria en el testimonio) trabajan de manera semejante, con huellas y restos, por medio de jirones y esquirlas, con palabras perdidas, desmembradas, en ruinas y desde las ruinas. Es que lo literario pareciera orbitar sobre formas diferentes a las corrientes de acceso al conocimiento de lo real, planteando una relación particular con respecto a esa realidad. Cierta heterodoxia de lo que es la realidad e incluso el interrogante filosófico de lo que por ella se entiende están en la base de sus fundamentos permanentemente movedizos, nunca fijos. Porque, en términos deleuzianos, la escritura es devenir incesante y no forma cerrada:

Escribir no es ciertamente imponer una forma (de expresión) a una materia vivida. La literatura está más bien del lado de lo informe, o de lo inacabado, como lo dijo e hizo Gombrowicz. Escribir es un asunto de devenir, siempre inacabado, siempre en vías de hacerse, y que desborda toda materia vivible o vivida. La escritura es inseparable del devenir (DELEUZE, 2006, p. 13).

Lo informe, lo inacabado, lo fragmentario que prolifera en el mismo fragmento, la escritura que deviene literatura, pero también la literatura que es devenir perpetuo de la escritura. Todo esto hace que lo literario permita ver y captar, aunque más no sea en potencia, aquellos aspectos de la realidad y de la imaginación, de la historia y de la memoria, difíciles, arduos, controversiales, polisémicos, irreductibles a palabras, a lenguaje, a discurso.

Proponemos tomar dos textos literarios a los efectos de ejemplificar y articular lo presentado hasta ahora, esto es, las ideas benjaminianas sobre la literatura y la historia y los rasgos del testimonio y la memoria. En ambos textos, destacan dos imágenes benjaminianas: por un lado, se compone una figura de autor análoga a la del trapero que rescata lo que la sociedad descarta, para convertirlo, en este caso, en literatura y hacer de ello una iluminación profana, donde el contenido de verdad de la obra de arte muestra el plus significante de lo literario; por otra parte, se escriben historias a contrapelo de la gran historia, no sólo en cuanto a su contenido, sino además en relación con la forma misma de escribir la historia. En este sentido, veremos cómo estos dos textos exhiben el modo en el que lo literario se constituye en matriz discursiva adecuada frente a un referente inasible como lo es lo traumático. Tal como se postula desde las primeras teorías de la literatura, la de los formalistas rusos, la forma es el contenido e, inversamente, el contenido da la forma textual. De todas maneras, no llevaremos a cabo un análisis textual de estos libros sino que formularemos un comentario general a partir de algunos de sus paratextos y su análisis discursivo, que permiten aproximarnos a ellos. Finalmente, y en cuanto a la conformación del corpus: por un lado, el texto de Sued significa una disrupción en la serie narrativa sobre la dictadura, puesto que es una de las poquísimas novelas que de principio a fin experimentan con el lenguaje, Asimismo, esta experimentación con el lenguaje no sería posible ni aceptada por otros discursos. Por otra parte, elegimos a Gorini en tanto que no es un escritor de ficción, sino que su incursión en lo literario responde a una expresa necesidad de poder rescatar testimonios y memorias que de otra forma se 
perderían.

Susana Romano Sued es escritora, docente, crítica literaria y traductora. El 24 de junio de 1977 fue secuestrada por la dictadura entonces imperante en Argentina. En 2007, publica su novela Procedimiento. Memoria de La Perla y La Ribera (2007). Se trata de una ficción testimonial, una novela experimental o, como ella y otras autoras la han definido, experiencial, puesto que transforma en relato la experiencia traumática y del horror narrada desde el centro, en un doble sentido: el centro clandestino de detención, tortura y exterminio (CCDTyE) como lugar desde el cual se enuncia, esto es, el centro mismo del horror (los lugares son los mencionados en el título). La novela se escribe desde las ruinas de un lenguaje y una historia que se dejan ver en la materialidad del libro como objeto semiótico: la tapa del libro está literalmente rota, tiene sólo una mitad, que deja ver otra tapa completa que asoma por debajo, como el testimonio y su memoria subterránea emergen a lo largo de una textualidad rota, en ruinas.

Si tomamos en cuenta algunos de sus paratextos, tenemos, en primer lugar, el título, el cual hace uso de la dilogía. Por un lado, alude al procedimiento represivo propio del período en cuestión, que podría resumirse en la secuencia persecución-secuestro-tortura-desaparición. El término a su vez hace uso del eufemismo, ${ }^{7}$ que esconde precisamente esa secuencia del accionar militar. En otra instancia, se configura el sentido literario: el procedimiento como sinónimo de artificio, el trabajo con la materialidad del lenguaje. En esta dirección, el escrito trabaja con la materialidad del lenguaje en un sentido experimental, emulando la lengua y el habla del CCDTyE, tanto de las víctimas como de los victimarios. Se trata de una lengua desarticulada, dislocada, en ruinas diríamos con Benjamin. En efecto, el encabezado de cada página muestra este lenguaje roto, hecho de vacíos, fisuras, espacios en blanco; la palabra violentada queda simbolizada en la forma de escritura del título: "PR CE IM EN ". Uno de los procedimientos más notorios y estudiados por la crítica consiste en la omisión de todos los artículos, como metáfora del intento de supresión de toda identidad de los secuestrados, por parte de los victimarios, en los CCDTyE. Mientras que los artículos particularizarían e individuarían, el objetivo de los represores era, precisamente, el contrario: anular la subjetividad así como la identidad de sus víctimas. Así vemos que esa sintaxis y morfología dislocadas son, al fin y al cabo, "más realistas" -como veíamos con la experiencia contada por Gamerro- que cualquier otra forma que pudiera adquirir el lenguaje y la lengua, puesto que emula esa habla en el CCDTyE. Imita sus silencios, sus interrupciones, sus sobresaltos cada vez que los genocidas descubrían a alguien haciendo uso de una palabra prohibida. Silencios que a su vez aluden a otros: silencios en el CCDTyE pero también sobre el centro, silencios en la sociedad durante la dictadura y en la posdictadura, censuras y autocensuras, silencios causados por lo que no se puede decir, nombrar, representar, silencios porque no existen las palabras para dar cuenta de ello, pero también por lo que no se quiere decir por el dolor que causa, por lo difícil que resulta acercarse al trauma. Silencios que, a la vez que los representa, son enfrentados por la literatura. Esa sintaxis entrecortada es equivalente, entonces, a la supresión de palabra en el CCDTyE, así como, en un plano más general, durante la vida del país en dictadura. El lenguaje, por acción y omisión, también sufrió violencia: la imposición del silencio y consecuente supresión del habla, ${ }^{8}$ la eliminación de ciertos vocablos, la prohibición de ciertas lenguas son algunas pruebas

\footnotetext{
${ }^{7}$ Pilar Calveiro, sobre el lenguaje eufemístico de los perpetradores, sostiene: "Es significativo el uso del lenguaje, que evitaba ciertas palabras reemplazándolas por otras: en los campos no se tortura, se 'interroga', luego los torturadores son simples 'interrogadores'. No se mata, se 'manda para arriba' o 'se hace la boleta'. No se secuestra, se 'chupa'. No hay picanas, hay 'máquinas'. No hay asfixia, hay 'submarino'. No hay masacres colectivas, hay "traslados'” (42).

${ }^{8}$ Sobre la violencia política y el lenguaje han teorizado numerosos autores. Hannah Arendt explica esta violencia
} 
de ello.

Por otra parte, esta lengua entrecortada, verborrágica por momentos, decantada en enumeraciones caóticas, emula la forma del testimonio: con incoherencias, espacios en blanco, vacíos, fisuras. Aquí, las especificidades de lo literario, lícitas para ese lenguaje testimonial, se revelan como una de las formas idóneas para presentar la voz testimonial que rescata los hechos de su memoria. Mientras que en otros discursos este lenguaje dislocado sería desestimado por incorrecto, lo literario rescata esas mismas ruinas del lenguaje puesto que entiende que, precisamente y como veíamos en el segundo apartado, el testimonio vale por lo que falta en él: "por su incoherencia factual, su confusión, su informalidad" (ŽIŽEK, 2013, p. 12). Donde no habría lenguaje, en esa habla entrecortada del CCDTyE, el sujeto que enhebra el enunciado rescata un discurso valioso. El procedimiento literario, entonces, resulta de vital importancia al momento de narrar esta para-experiencia fundada en el seno del horror.

Retomando los paratextos, encontramos dos epígrafes. Tomaremos en consideración el primero, el cual es una reflexión que pertenece a Johan Baptist Metz y a Elie Wiesel. Lo transcribimos completo:

....una forma de conservar el dolor del recuerdo en la cultura, significa en cuanto a la narración una coalición entre los que viven actualmente y los que ya han muerto, los olvidados, los sacrificados, vencidos. Sus visiones y sabidurías forman parte del acervo de la humanidad; ese acervo no se consigue nunca únicamente a través de la reconstrucción histórica. Eso sólo es posible narrando en contra del tiempo, y por eso hay que intentar contar,

sobre el lenguaje como la anulación de la política: "Pero que quede claro que ni siquiera las guerras, por no hablar de las revoluciones, están determinadas totalmente por la violencia. Allí donde la violencia es señora absoluta, como por ejemplo en los campos de concentración de los regímenes totalitarios, no sólo se callan las leyes -les lois se taisent, según la fórmula de la Revolución Francesa-, sino que todo y todos deben guardar silencio. A este silencio se debe que la violencia sea un fenómeno marginal en la esfera de la política, puesto que el hombre, en la medida en que es un ser político, está dotado con el poder de la palabra. Las dos famosas definiciones que dio Aristóteles del hombre (el hombre como ser político y el hombre como ser dotado con la palabra) se complementan y ambas aluden a una experiencia idéntica dentro del cuadro de vida de la polis griega. Lo importante aquí es que la violencia en sí misma no tiene la capacidad de la palabra y no simplemente que la palabra se encuentre inerme frente a la violencia. Debido a esta incapacidad para la palabra, la teoría política tiene muy poco que decir acerca del fenómeno de la violencia y debemos dejar su análisis a los técnicos. En efecto, el pensamiento político sólo puede observar las expresiones articuladas de los fenómenos políticos y está limitado a lo que aparece en el dominio de los asuntos humanos, que, a diferencia de lo que ocurre en el mundo físico, para manifestarse plenamente necesitan de la palabra y la articulación, esto es, de algo que trascienda la visibilidad simplemente física y la pura audibilidad" (1992, p. 19). David Le Breton sostiene que "si la modernidad maltrata el silencio, no debemos olvidar que cualquier empeño dictatorial empieza matando la palabra” (2006, pp. 5-6). El carácter relacional del lenguaje queda conculcado si se practica la violencia sobre él. La relación con el otro por medio de la palabra, oyente y también hablante, es puesta en peligro: "El lenguaje implica a menudo relacionarse con el otro: en esto también el lenguaje ha sido perseguido por las dictaduras, en producir un silencio que no solamente genere desinformación, sino que también rompa el vínculo con el resto y que destruya los vasos comunicantes y relacionales de los diferentes grupos" (LE BRETON, 2006, p. 80). Alejandro Kaufman expone: "El lenguaje, ya podemos inferirlo de otras experiencias históricas y testimoniales, no permaneció incólume ante el horror" (2007, p. 125). Marguerite Feitlowitz explica las diferentes formas que adquirió la violencia sobre el lenguaje durante la dictadura en Argentina. Algunas de ellas: "1) envolver en misterio sus verdaderas acciones e intenciones; 2) expresar el sentido opuesto al de sus palabras; 3) inspirar confianza, tanto en el país como en el extranjero; 4) infundir culpa, en especial en las madres, para consolidar su complicidad; y 5) sembrar terror paralizante y confusión. La retórica oficial muestra todos los rasgos que asociamos con los discursos autoritarios: obsesión con el enemigo, oratoria triunfal, abstracción exagerada y lemas mesiánicos, todo basado en la 'verdad absoluta' y la 'realidad objetiva'” (2015, p. 54). 
contar una y otra vez (ROMANO SUED, 2012, p. 9).

Al fragmento subyacen tres factores centrales que dan base al presente trabajo. Por un lado, la importancia de la memoria, resumida en la frase "conservar el dolor del recuerdo en la cultura". Asimismo, la relevancia del testimonio, esa narración que vincula a "los que los que ya han muerto, los olvidados, los sacrificados, vencidos". La novela marca, a través del epígrafe, su línea filiatoria en el testimonio y la memoria. Por otro lado, la cita manifiesta firmemente la convicción de que no hay posibilidad de construir ese acervo "nunca únicamente a través de la reconstrucción histórica”. En este sentido, se apela a otras discursividades que den cuenta del pasado y lo conviertan en memoria, mediante esa lectura a contrapelo que proponía Benjamin, "narrando en contra del tiempo". El texto literario apela a esa deconstrucción/destrucción de la temporalidad. Estas dislocaciones temporales se ven cristalizadas en otros paratextos, a saber, los subtítulos que encabezan cada capítulo. Mediante ellos se opera deliberadamente una desestructuración del tiempo, desde el momento en el que rompen con la cronología temporal lógica. Por ejemplo, al "Día ocho, de tarde entre 4 y 5 " le continúa el "Día dos. Cero hora", así como al "Día mil treinta y cuatro, catorce horas" le sigue el "Día dos, 44 hs. Noche". De igual manera, la entrada del "Día seis y medio" está marcada por la "hora de sed y llagas". Hay, pues, una ostensible deconstrucción de la temporalidad, en parte como forma de deconstrucción de ese tiempo histórico lineal y homogéneo, al que se le opone un "tiempo subjetivo", al decir de Kosellek (1993), como forma de alertar sobre la artificiosidad del tiempo del discurso de la historia. Ese tiempo individual y particular está dado por el eterno presente en el que se funda la novela: el que no permite salir del CCDTyE, donde las horas y los días son todos iguales a causa del secuestro. Esos fragmentos de tiempo desordenados son, a su vez, manifestación de la fragmentariedad del relato, de la historia a contar. Por un lado, una escritura que es siempre fragmentaria por el hecho de ser relato: abarcar la totalidad es imposible. Por otra parte, el fragmento se opone a la pretensión histórica de esa totalidad, con lo que desde su misma forma, y como lo venimos viendo a partir de los procedimientos del lenguaje, el texto se constituye a la manera de lectura a contrapelo de la historia: a contrapelo no sólo de su contenido (una historia alternativa al poder de aquel entonces, una memoria subterránea), sino también a contrapelo de las leyes historiográficas del lenguaje preciso, la objetividad y la totalidad.

En este sentido, la novela reivindica los rasgos del testimonio y los de la memoria (en efecto, desde el subtítulo se inscribe la novela en lo memorial), análogos a la forma literaria: lo fragmentario, lo selectivo, lo puntual de una vivencia frente a las generalizaciones de la historia. Sin embargo, y como veremos con Gorini, no se trata de una oposición (al estilo del clásico contraste memoria-historia) sino de un gesto que viene a plantear lo literario como complemento, como forma idónea para rescatar esos restos descartados por otros regímenes discursivos, aportando su perspectiva singularizada en cuanto a forma y contenido. Así, el texto reivindica la literatura testimonial desde el momento en el que incluye como segundo epígrafe un poema del sobreviviente Paul Celan, traducido por la propia autora. Los dos párrafos iniciales, que ofician a la manera de introducción, enmarcan el texto en el campo literario, por la intertextualidad que operan con el Quijote: mientras la primera oración sitúa vagamente el lugar al estilo cervantino, la última de esta introducción entrecruza literatura y testimonio, en un gesto autorreferente: "En ese mismo lugar fue encontrado el atado de trapos envolviendo los papeles con los testimonios" (2012, p. 19). Este reconocimiento al papel de la literatura testimonial se refuerza con el poema, nuevamente de Celan, que se incluye al finalizar la novela.

Por su parte, Ulises Gorini es quien escribió la más exhaustiva historia de las Madres de Plaza de Mayo. Publicó dos importantes y extensos tomos sobre tal historia, La rebelión de las 
Madres (2011) y La otra lucha (2011). No obstante, a pesar de lo extenso de tales libros, hubo testimonios, relatos, historias al fin, que quedaron fuera. La razón: no cuadraban en el marco de las leyes del discurso historiográfico. De este modo, en 2017 publica el libro La venganza y otros relatos. En él, incluye relatos que las Madres le contaron pero que no cuadraban en las leyes del discurso historiográfico, con lo que no formaron parte de sus dos tomos. Se modulan relatos acerca de micro resistencias de las Madres frente a un poder autoritario en todos sus niveles, historias que hacen coincidir en una misma noche nietos perdidos y abuelas que nunca supieron de ellos, relatos que rozan los límites del género fantástico, donde el hijo desaparecido siempre está presente, argumentos en los cuales lo onírico es parte de la matriz discursiva, tramas, en fin, en las que las dudas son más (y más reveladoras) que las certezas.

Pero por encima de los relatos, nos abocamos a los paratextos, puesto que hacen explícita la consciencia de su propio discurso literario, abrevando de las teorías que dimensionan la literatura como aquel discurso que recupera lo que excede a otras prácticas discursivas y regímenes de la palabra. Los paratextos hacen explícito el principio constructivo de la materia literaria: se fundan en un gesto de rescate de memorias y testimonios que no se incluyen en la gran historia y que además se articulan en la clave del relato literario, la pequeña historia, el testimonio mínimo, restos que hacen a esa historia hecha y deshecha en las ruinas y por ellas. Gorini necesitó "pensar poéticamente", hacer uso de lo metafórico literario en este gesto de rescate de historias que no cuadraban en otros lenguajes más que el literario.

En el "Prólogo", Dora Barrancos recalca, no sin cierto vuelo poético, el motivo de la escritura de los relatos de Gorini, dejando al descubierto los hilos de la historia y de las historias, de una escritura ficcional y simultáneamente, la necesidad de distanciarse del registro historiográfico:

Pero quedaron numerosas endechas, flotaron tantísimos recuerdos y hasta ensoñaciones que no pudieron caber en la trama que constituyeron La rebelión de las Madres (1976-1983) y La otra lucha (1983-1986), los libros que dedicó Ulises Gorini a la historia de la resistencia de las Madres. Había que darles una oportunidad literaria, un desprendimiento de las más austeras reglas historiográficas. Las voces de estas mujeres engarzan circunstancias vividas con situaciones imaginarias, que si no tuvieron plausibilidad empírica (BARRANCOS APUD GORINI, 2018, p. 5).

El libro es prueba fehaciente de cómo un historiador recurre a la lengua poética de la literatura, a la forma literaria y, con ello, a sus especificidades, a los efectos de rescatar esos testimonios de las Madres, esas memorias que pervivieron a lo largo del tiempo y que sólo estaban esperando encontrar el lenguaje que les resultara idóneo, la forma discursiva que les hiciera: la literaria.

Luego, en la presentación al volumen, el propio autor advierte el distanciamiento del terreno historiográfico vía la ficción. Es que si de distanciarse se trata, qué mejor que la literatura. Como ya lo establecieron los formalistas, el arte opera por extrañamiento, singularizando lo que tenemos cristalizado por acción de la costumbre, haciéndonos ver y no simplemente reconocer los objetos o realidades (SHKLOVSKI, 1978, p. 60). Por ello, a diferencia de la disciplina histórica, la literatura se funda en el gesto de plantear preguntas más que brindar respuestas. He aquí uno de los distanciamientos de la historia: "Este libro, en cambio, no pretende ofrecer explicaciones. Aunque su origen se remonta a aquella experiencia investigativa, su aporte busca ser otro" (GORINI, 2018, p. 10). Surgen, entonces, esos "otros 
relatos” por fuera de los dos tomos que hicieron a la gran historia de las Madres:

En efecto, mientras entrevistaba a las Madres que generosamente me abrieron sus casas, sus archivos y sus corazones para reconstruir esa dramática, heroica y maravillosa historia, al tiempo que iban apareciendo las líneas que dibujaban el recorrido colectivo que las llevó a convertirse en un nuevo sujeto político decisivo de nuestro pasado inmediato y de nuestro presente, fui recogiendo otros relatos que, aunque eran parte del camino que tuvieron que recorrer, no siempre cabían en aquella narración más general (p. 10).

El historiador se inviste ahora del rol de trapero, diríamos con Benjamin, quien rescata, por medio de la forma literaria, las historias que él mismo había descartado de la gran historia: frente a la historia y su discurso no exento de normas, la literatura viene a constituir el terreno propicio para recuperar esas memorias. De la misma manera, este trapero que recata en lo literario lo que la sociedad descarta, aquello que no encaja en las normas y saberes disciplinares canónicos, pone a funcionar en sus escritos la tesis sobre filosofía de la historia que veíamos al comienzo, aquella según la cual la historia debe ser leída a contrapelo: ${ }^{9}$ a contracorriente de su propia historia de las madres, el autor lee en esas pequeñas historias, indaga en esos testimonios, lee y reconstruye aquellas memorias, sabiendo que también allí, en la conversión de los testimonios y memorias en literatura, se producen esas iluminaciones profanas de las que no hablaba Benjamin con su pensar poéticamente. Asevera Gorini: "Estoy seguro de que, de un modo distinto - quizá complementario en relación con la historia más general, o, si se quiere, con la historia en un sentido disciplinar-, estos relatos pueden servir para comprender a estas mujeres más que muchos análisis" (2017, p. 10).

En los relatos que componen este volumen, priman la figura del testimonio -las Madres que relatan, narran, cuentan, traman sus voces como quien teje su historia de vida- y de la memoria. Por un lado y si, como entiende Ricoeur, el testimonio es el paso obligado de la historia (2003, p. 41), en este caso, aun cuando no llegue a convertirse en discurso historiográfico, el testimonio de las Madres es recuperado. Más todavía, se lo valora como tal sin necesidad de convertirse estrictamente en discurso de la historia. Por otra parte, los relatos son memoria de lo mínimo, pequeño y fragmentario que viene a complementar el rompecabezas de la memoria social. Es que, al igual que la individual, la memoria colectiva se construye de esos fragmentos que, por ser tales, rescata la literatura.

\section{Consideraciones finales}

Veíamos con Benjamin que toda literatura, y más aún la que trabaja con el horror como materia prima, se constituye sobre aquello que la sociedad descarta, con los restos que no son productividad según la lógica capitalista. De allí que el escritor se convierta en el trapero que vagabundea entre las ruinas y recoge de ellas lo que será objeto de su escritura. Asimismo, con su práctica escritural relee la historia a contrapelo, tanto en lo que tiene que ver con la forma como con el contenido de la historia. En el caso de la literatura testimonial observamos además que se construye sobre dos variables, como mínimo, íntimamente relacionadas: el testimonio y

\footnotetext{
${ }^{9}$ Como lo entiende Nicolás Rosa desde su concepción psicoanalítica, "lo que define a la literatura es ese menos donde se afirma y se funda. Una falta histórica, sociológica, psicoanalítica (para mencionar los saberes dominantes) que la revela como lo faltante del discurso social, como lo no-dicho del discurso colectivizado” (1987, p. 11).
} 
la memoria. A ellas subyace la problemática de la representación instalada en el lenguaje, el relato y el discurso. Pues sucede que las historias atravesadas por lo traumático profundizan la opacidad entre las palabras y las cosas a las que ellas refieren sólo indirectamente.

Con Susana Romano Sued y Ulises Gorini planteamos dos ejemplos de esta literatura que tiene como causa y a la vez efecto la memoria, individual y colectiva. Ambos autores asumen la investidura del trapero que recoge lo que otros discursos descartan, encontrando la forma más adecuada a ellos, la de lo literario. En el caso de Romano Sued, la elección de la forma literaria, con sus estrategias del discurso específicas, su trabajo con procedimientos que moldean la materialidad del lenguaje y su reflexión, desde lo paratextual, del papel de la literatura, notamos el modo por el cual la forma literaria, su discurso y sus singularidades, son los adecuados a los efectos de mostrar ese lenguaje en ruinas propio del testimonio. Así, desde la misma forma se escribe una historia a contrapelo que relee aquella escrita por los genocidas y por sus aliados políticos aun en democracia, del mismo modo que relee la forma propia de hacer historia. La novela de esta autora es testimonio que, como tal, aporta a la memoria colectiva. Por su parte, el libro de Gorini construye desde sus paratextos una imagen específica de la literatura: la de aquella que viene a recoger lo que de otra manera se perdería, concretamente, aquella que viene a decir, gracias a sus especificidades, lo que otros discursos no pueden debido a las limitaciones dadas por las leyes y reglas que le son propias. Los testimonios de las Madres se transforman en relatos que encuentran su forma en la literatura, en una escritura ficcional que recupera la memoria entre las ruinas y desde ellas, pasando el cepillo a contrapelo de la historia. Debido a sus rasgos específicos (subjetividad, discontinuidad, fragmentariedad, entre otros), el testimonio y la memoria logran condensar la intensidad de sus constelaciones significantes (muchas veces ocultas, como lo entendía Benjamin) en ese discurso que dice, expone, interpreta aun cuando no se lo propone: el literario.

\section{Referencias}

AGAMBEN, G. Lo que queda de Auschwitz. El archivo y el testigo. Valencia: Pre-Textos, 2010.

ARENDT, H. Hombres en tiempos de oscuridad. Barcelona: Gedisa, 1990.

ARENDT, H. Sobre la revolución. Buenos Aires: Alianza Editorial, 1992.

AUGÉ, M. Las formas del olvido. Barcelona: Gedisa, 1998.

BACHElARD, G. La poética del espacio. Buenos Aires: Fondo de Cultura Económica, 2000.

BENJAMIN, W. Infancia en Berlin hacia 1900. Madrid: Alfaguara, 1987.

BENJAMIN, W. Las Afinidades electivas de Goethe. En: . Obras completas. Libro 1, vol. 1. Madrid: Abada, 2006.

BENJAMIN, W. Charles Baudelaire. Un lírico en la época del altocapitalismo. En: Obras completas. Libro I, vol. 2. Madrid: Abada, 2008.

BENJAMIN, W. Estética y política. Buenos Aires: Las Cuarenta, 2009.

CALVEIRO, P. Poder y desaparición. Los campos de concentración en Argentina. Buenos Aires: Colihue, 2006.

CANCLINI, R. Ficción y verdad en las narraciones: función política de la memoria. In 
ZUBIETA, A. (comp.). La memoria. Literatura, arte y política. Bahía Blanca: Universidad Nacional del Sur, 2008.

CARNOVALE, V. Aportes y problemas de los testimonios en la reconstrucción del pasado reciente en la Argentina. En: FRANCO, M.; LEVÍN, F. (comp.). Historia reciente. Perspectivas y desafios para un campo en construcción. Buenos Aires: Paidós, 2007.

DELEUZE, G. La literatura y la vida. Córdoba: Alción editora, 2006.

FEIERSTEIN, D. Memorias y representaciones. Sobre la elaboración del genocidio. Fondo de Cultura Económica, 2012.

FEITLOWITZ, M. Un léxico del terror. Ciudad Autónoma de Buenos Aires: Prometeo, 2015.

FOUCAULT, M. Las palabras y las cosas. Barcelona: Planeta-Agostini, 1985.

FOUCAULT, M. Esto no es una pipa. Ensayo sobre Magritte. Buenos Aires: Eterna Cadencia, 1973.

FUKS, J. La resistencia. Ciudad Autónoma de Buenos Aires: Literatura Random House, 2018.

GORINI, U. Madres de Plaza de Mayo. La venganza y otros relatos. Ciudad Autónoma de Buenos Aires: La Página, 2018.

JABLONKA, I.; WIEVIORKA, A. (comp.). Nuevas perspectivas sobre la Shoá. Bernal: Universidad Nacional de Quilmes, 2017.

JELIN, E. ¿Quiénes? ¿Cuándo? ¿Para qué? Actores y escenarios de las memorias. En: VINYES, R. (ed.). El Estado y la memoria. Buenos Aires: Del nuevo extremo, RBA (España), 2009.

JELIN, E. Los trabajos de la memoria. Lima: Instituto de Estudios Peruanos, 2012.

KAUFMAN, A. Los desaparecidos, lo indecible y la crisis. Memoria y ethos en la Argentina del presente. In FRANCO, M.; LEVÍN, F. (comp.). Historia reciente. Perspectivas y desafios para un campo en construcción. Buenos Aires: Paidós, 2007.

KOHAN, M. El país de la guerra. Buenos Aires: Eterna cadencia, 2014.

KOSElleK, R. Futuro pasado. Para una semántica de los tiempos históricos. Barcelona: Paidós, 1993.

LE BRETON, D. El silencio. Madrid: Sequitur, 2006.

LINK, D. Qué se yo. Testimonio, experiencia y subjetividad. En: VALLINA, C. (ed.). Crítica del testimonio. Ensayos sobre las relaciones entre memoria y relato. Rosario: Beatriz Viterbo Editora, 2008.

MEYER, E.; SALGADO, E. Un refugio en la memoria. La experiencia de los exilios latinoamericanos en México. México: Océano, 2002.

MONTESPERELLI, P. Sociología de la memoria. Buenos Aires: Nueva Visión, 2004.

NANCY, J. L. La representación prohibida. Buenos Aires: Amorrortu, 2006.

PIPER, I. Investigación y acción política en prácticas de memoria colectiva. En: VINYES, R. (ed.). El Estado y la memoria. Buenos Aires: Del nuevo extremo, RBA (España), 2009.

POLLAK, M. Memoria, olvido, silencio. La producción social de identidades frente a situaciones límite. La Plata: Al margen, 2006.

PRADELLI, A. En mi nombre. Historias de identidades restituidas. Ciudad Autónoma de Buenos 
Aires: Paidós, 2014.

RANCIÈRE, J. Politica de la literatura. Buenos Aires: Libros del zorzal, 2011.

RANCIÈRE, J. Figuras de la historia. Buenos Aires: Eterna Cadencia, 2013.

RICOEUR, P. La memoria, la historia, el olvido. Buenos Aires: Fondo de Cultura Económica, 2003.

ROBIN, R. La memoria saturada. Buenos Aires: Waldhuter, 2012.

ROMANO SUED, S. Procedimiento. Memoria de La Perla y La Ribera. Buenos Aires: El asuntoMilena Caserola, 2012.

ROSA, N. Estos textos, estos restos. Los fulgores del simulacro. Cuadernos de extensión universitaria, Santa Fe, Universidad Nacional del Litoral, n 15, pp. 9-18, 1987.

SARLO, B. Política, ideología y figuración literaria. In: BALDERSTON, D. et al. Ficción y política. La narrativa argentina durante el proceso militar. Buenos Aires: Alianza, 1987.

SARLO, B. Siete ensayos sobre Walter Benjamin. Buenos Aires: Siglo veintiuno editores, 2011.

SHKLOVSKI, V. El arte como artificio. En: TODOROV, T. (comp.). Teoría de la literatura de los formalistas rusos. México: Siglo XXI, 1978.

STEINER, G. Extraterritorial. Buenos Aires: Adriana Hidalgo, 2009.

TEUBAL, R.; BETTANIN, C.; VEIGA, C.; VIllalBA, M.; PALACIOS, A.; RODRÍGUEZ, M. Memorias fraternas. La experiencia de hermanos de desaparecidos, tíos de jóvenes apropiados durante la última dictadura militar. Buenos Aires: Eudeba, 2010.

TINIANOV, J. Sobre la evolución literaria. En: TODOROV, T. (comp.). Teoría de la literatura de los formalistas rusos. México: Siglo XXI, 1978.

TODOROV, T. Introducción. En: BARTHES, R. et. al., Lo verosimil. Buenos Aires: Tiempo Contemporáneo, 1970. Pp. 11-15.

TRAVERSO, E. El pasado, instrucciones de uso. Buenos Aires: Prometeo, 2011.

VIRNO, P. El recuerdo del presente. Ensayo sobre el tiempo histórico. Buenos Aires: Paidós, 2003.

WHITE, H. Metahistoria. La imaginación histórica en la Europa del siglo XIX. México: Fondo de Cultura Económica, 1992.

WITTGENSTEIN, L. Tractatus logico-philosophicus. Madrid: Alianza, 1973.

ŽIŽEK, S. Sobre la violencia. Seis reflexiones marginales. Buenos Aires: Paidós, 2013.

Recebido em: 17/05/2020

Aceito em: 28/06/2020 